\title{
In-Situ Measurements of the Photoconductivity of Multi-Layered Organic Photovoltaic Devices Using Impedance Spectroscopy
}

\author{
Ryoji Maeda1,2*, Hiroshi Tokairin², Jun-Ichi Takahashi², Yuji Yoshidaa,3 \\ ${ }^{1}$ Interdisciplinary Graduate School of Science and Engineering, Tokyo Institute of Technology, \\ Yokohama, Japan \\ ${ }^{2}$ Advanced Technology Research Laboratories, Idemitsu Kosan Co., Ltd., Sodegaura, Japan \\ ${ }^{3}$ Research Center for Photovoltaic Technologies, AIST, Tsukuba, Japan \\ Email: ${ }^{\text {ryoji.maeda@idemitsu.com }}$
}

Received 20 December 2014; accepted 26 January 2015; published 28 January 2015

Copyright $@ 2015$ by authors and Scientific Research Publishing Inc.

This work is licensed under the Creative Commons Attribution International License (CC BY). http://creativecommons.org/licenses/by/4.0/

(c) ()

\begin{abstract}
In-situ impedance spectroscopy (IS) observations of the photoconductivity of the carriers induced by photo-irradiation in organic hetero-junction structured photovoltaic devices are presented. In the IS measurements, the externally applied voltage and the dependence of the light intensity applied to the device were investigated. Analysis of the frequency characteristics which was measured by changing the light intensity shows there is a proportional relationship between the changes in the conductivities of the two components. The mobilities of the CuPc and C60 layers were calculated from the conductivities and were in the orders of $10^{-4}$ and $10^{-3} \mathrm{~cm}^{2} / \mathrm{Vs}$, respectively.
\end{abstract}

\section{Keywords}

Organic Photovoltaic Cells, Impedance Spectroscopy, Modulus Analysis, Photoconductivity

\section{Introduction}

Impedance spectroscopy (IS) is a powerful tool for analyzing the electrical properties of devices, especially for capacitance-voltage analyses, which have become standard methods to investigate device characteristics. Re-

${ }^{*}$ Corresponding author.

How to cite this paper: Maeda, R., Tokairin, H., Takahashi, J.-I. and Yoshida, Y. (2015) In-Situ Measurements of the Photoconductivity of Multi-Layered Organic Photovoltaic Devices Using Impedance Spectroscopy. Advances in Materials Physics and Chemistry, 5, 47-52. http://dx.doi.org/10.4236/ampc.2015.52007 
cently, IS has also been extensively applied to organic devices, such as organic light-emitting diodes [1]-[5], organic photovoltaic (OPV) cells [6] [7] and organic thin-film transistors [8] [9], revealing the electrical properties including the carrier injection [1] [2] and charge transport properties [3]-[5].

Along with IS measurements, other methods have been used to measure the mobility in highly resistive organic semiconductor films and other materials including the time-of-flight (TOF) method [10] [11], the dark injection (DI) transient method [12]-[15], a method to obtain the mobility from the I-V characteristics of the space charge limited current (SCLC), time-resolved electroluminescence (EL) spectroscopy [16] and the photoexcited time-resolved microwave conductivity technique [17] [18]. To accurately evaluate the transit time using the TOF and DI methods, a film that is substantially thicker than the light-emitting layer in an organic EL device is required. Because the electronic and optical properties of an organic semiconductor largely depend on the film thickness [19], measurements should be performed on a film thickness which is equal to that in an actual device. In the SCLC method, measurements using the actual device structure are difficult and the electric-field dependence of the mobility cannot be determined. Time-resolved EL spectroscopy and photoexcited time-resolved microwave conductivity are methods used to evaluate the mobility under conditions that differ from the actual applied voltage. In contrast, IS measurements that enable the mobility to be measured in actual OPV devices and the electric-field dependency of the mobility can be evaluated. However, the photoconductivity in the low-voltage region, where an actual OPV device operates, has not been discussed. In all cases, the evaluation of the mobility under high-electric-field conditions, such as in the SCLC region, has been the main focus of discussion.

In this study, in-situ IS measurements of the photoconductivity of the carriers induced by photoirradiation in the layers in organic hetero-junction structured photovoltaic devices were performed. The IS measurements were carried out by changing the externally applied voltage and the intensity of the light irradiating the device. To establish a basic method, using the dependence of the frequency characteristics of the relaxation time on the light intensity, a change in the photo conductivity that originated from the carriers induced by photoirradiation in each layer was examined using a donor/acceptor hetero-structured device.

\section{Experimental Methods}

\subsection{Device Preparation}

The compounds CuPc, C60 and bathocuproine (BCP) were purchased from Sigma-Aldrich Co. Ltd. These materials were purified by vacuum sublimation at $10^{-3} \mathrm{~Pa}$. OPV devices with a layered structure were fabricated by vacuum deposition. The device structure was: indium tin oxide (ITO)/30 nm, copper phthalocyanine (CuPc)/ 60 $\mathrm{nm}, \mathrm{C} 60 / 10 \mathrm{~nm}$, bathocuproine (BCP)/100 nm Al. ITO substrates, purchased from Asahi Glass Co., Ltd., with a sheet resistance of $25 \Omega / \mathrm{sq}$ were ultrasonicated first in 2-propanol and then in ultra-pure water. They were later exposed to an ultraviolet-ozone surface treatment and transferred to a vacuum chamber. The organic materials were evaporated onto the substrates under a vacuum pressure of less than $10^{-4} \mathrm{~Pa}$, with deposition rates between 1 and $5 \AA / s$. The active area of the diodes was $5.8 \mathrm{~mm}^{2}$. The devices were measured in ambient atmosphere without encapsulation.

\subsection{Device Characterization}

The J-V characteristics of the devices were measured at room temperature with a source measurement unit (Keithley Instruments Inc., 2400) in the dark and under illumination of $100 \mathrm{~mW} / \mathrm{cm}^{2}$ white light provided by an AM 1.5 solar simulator.

The impedance measurements were performed with an impedance analyzer (Agilent Technologies Inc., 4294A) in the frequency range from $100 \mathrm{~Hz}$ to $1 \mathrm{MHz}$ in the dark. The AC modulation amplitude was kept as low as $50 \mathrm{mV}$, where the response to the AC amplitude was linear. The complex impedance data were transferred to a PC and processed mathematically to appropriate representations.

\section{Results and Discussion}

Figure 1(a) shows the configuration of the donor/acceptor heterostructured OPV device used in this study, the generation of an exciton accompanied by photoirradiation, and the process of generating holes and electrons at the interface between the donor and acceptor layers.

Figure 1(b) shows the dependency of the J-V characteristics on the light intensity. Under 1 sun of irradiance, 


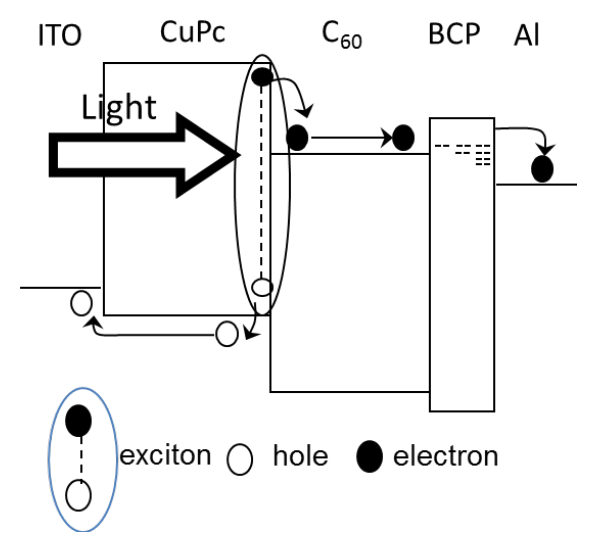

(a)

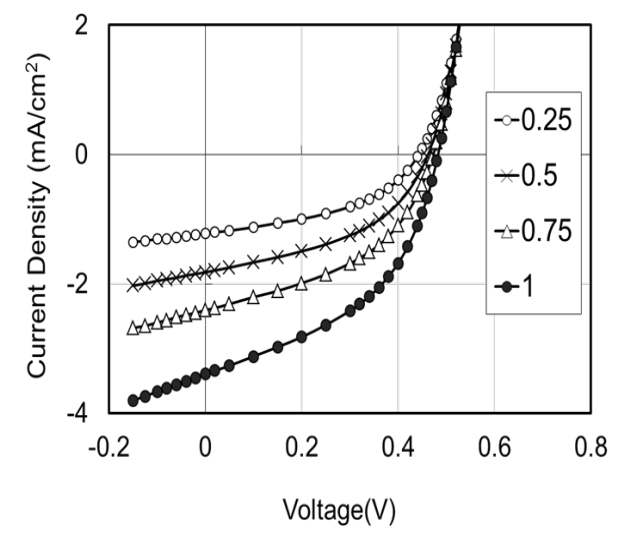

(b)

Figure 1. (a) Schematic energy diagram of the CuPc/C60 p-n hetero-junction photovoltaic device (The structure of the device: ITO/30 nm, CuPc/60 nm, C60/10 nm, BCP/100 nm Al); (b) J-V characteristics of an organic solar cell in the dark and under various illumination intensities of an AM 1.5 G simulated solar spectrum.

the device characteristics were: open circuit voltage, Voc $=0.48 \mathrm{~V}$, space charge current density, Jsc $=3.4 \mathrm{~mA}$ $\mathrm{cm}^{-2}$, fill factor, $\mathrm{FF}=0.46$, and the power conversion efficiency, PCE $=0.75 \%$. The threshold voltage was determined to be about $0.5 \mathrm{~V}$ from the $\mathrm{J}-\mathrm{V}$ characteristics (this is the voltage at which a large number of charges begin to be injected from the electrodes). The voltage range in which the device generates power as an OPV device, that is, the region where it operates, was $0-0.5 \mathrm{~V}$. This voltage range was smaller than the bias voltage at which the mobility and conductivities are evaluated by using conventional methods. This demonstrates the importance and necessity to evaluate the conductivity and carrier mobility within the actual driving-voltage region of an OPV, which is the purpose of this study.

Figure 2 shows Bode modulus plots for each bias voltage under 1 sun of irradiance, that is, the characteristics of the imaginary part of the modulus (Im M) versus frequency.

A change in the resistance component was observed because $\mathrm{M} \sim \mathrm{i} \omega \mathrm{Z}$, where $\omega$ is the angular frequency and $i$ is the imaginary part.

There are two components, each with a relaxation time that responds to the frequency. The time constants for these two components did not change in the region from 0 to $0.4 \mathrm{~V}$, which is equal to or below the threshold voltage. The conductivity within this voltage region depended on the frequency response.

From the formulas:

$$
\tau=\frac{1}{2 \pi f_{\text {peak }}}=R C
$$

where $\tau$ is the relaxation time, and $C=\varepsilon S / d$

$$
\sigma=\frac{1}{\rho}=\frac{d}{R S}
$$

where $S$ is the area and $d$ is the thickness of the layer

The peak frequency was derived from the following equation:

$$
f_{\text {peak }}=\frac{2 \pi}{\varepsilon} \sigma
$$

where $\sigma$ is the conductivity, $\rho$ is the electrical resistivity, $\varepsilon$ is the permittivity.

In the Bode plots, there was a proportional relationship between $f_{\text {peak }}$ and $\sigma$.

Figure 3(a) shows the dependency of the Bode plots on the light intensity at a bias voltage of $0.3 \mathrm{~V}$. The peak frequencies of the two components shifted, which is in agreement with the changes in the photo-induced carriers that were generated according to the light intensity.

Figure 3(b) shows plots of the peak frequency versus light intensity. The changes in the slopes for the two components were the same, which indicates that the main change was a shift in the conductivity of each layer, 


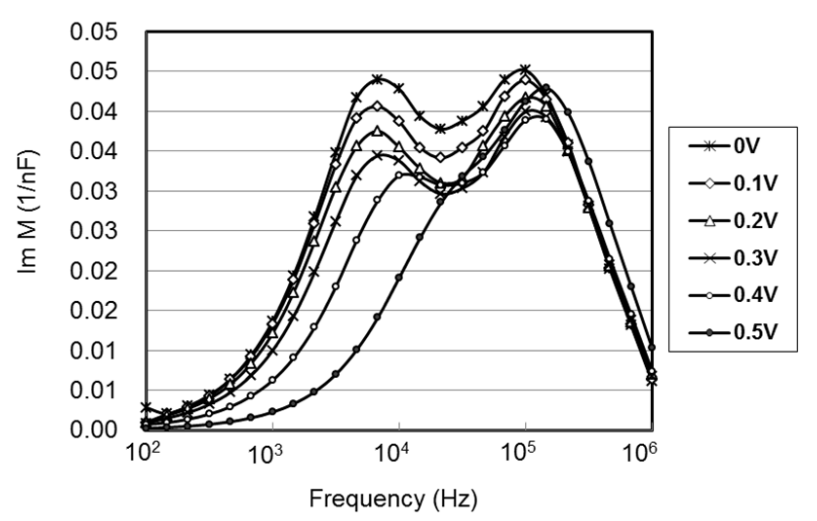

Figure 2. Bode modulus plots for each bias voltage under 1 sun of irradiance, that is, the characteristics of the imaginary part of the modulus (Im M) versus frequency.

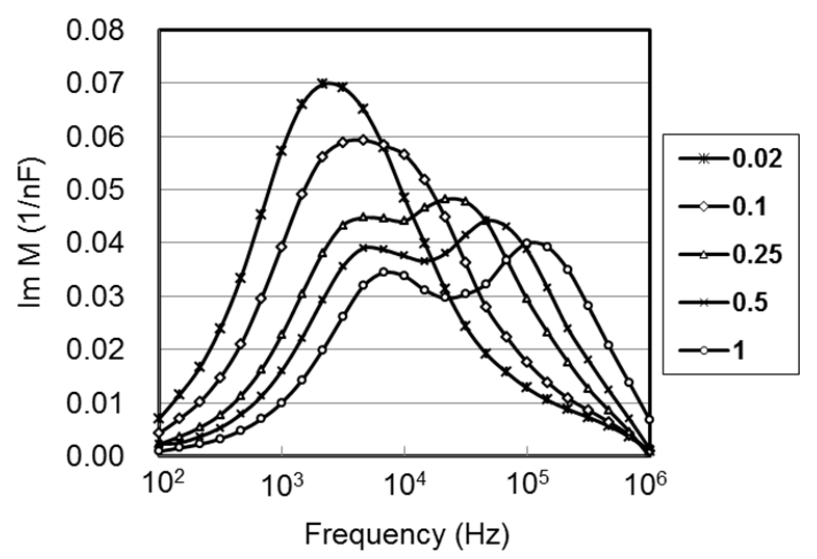

(a)

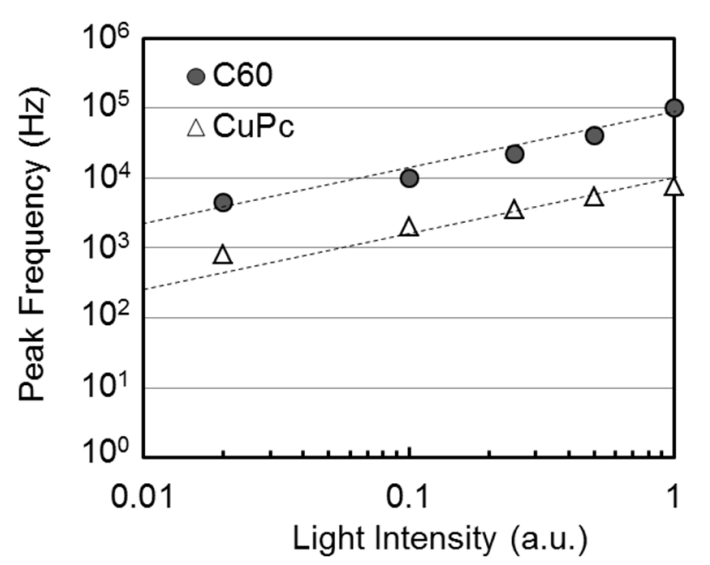

(b)

Figure 3. (a) Dependence of the Bode plots on the light intensity at a bias voltage of $0.3 \mathrm{~V}$; (b) Dependence of the peak frequency on the light intensity.

caused by holes and electrons being generated in equal amounts under light irradiation. The components of the relaxation time were identified from the dependency of the film thickness for each layer. The component in the low-frequency region was found to be CuPc and that in the high-frequency side was found to be C60. Given that the ratio of the peak frequency was a single digit, the ratio between the carrier mobility of the CuPc layer and the C60 layer was calculated to be a single digit using the formula:

$$
\sigma=\mu \cdot n \cdot e
$$

where $\mu$ is the carrier mobility, $n$ is the carrier density and $e$ is the elementary charge.

Figure 4 shows the $\sigma_{\mathrm{AC}}$ values (AC electrical conductivity) at bias voltages from 0 to $0.5 \mathrm{~V}$ for an OPV device under 1 sun of irradiance. Using $\sigma_{\mathrm{AC}}=\mathrm{d} / \mathrm{AZ}$, the conductivity of the entire device was determined to be 1.0 $\mu \mathrm{S} / \mathrm{m}$ at $100 \mathrm{~Hz}$. The carrier mobility $\mu$ was calculated to be on the order of $10^{-3} \mathrm{~cm}^{2} / \mathrm{Vs}$ using $\mathrm{n}=10^{16} \mathrm{~m}^{-3}$. Therefore, because the mobility ratio between CuPc and C60 was only a single digit, the mobility of CuPc was calculated to be in the order of $10^{-4} \mathrm{~cm}^{2} / \mathrm{Vs}$, and that of C60 was in the order of $10^{-3} \mathrm{~cm}^{2} / \mathrm{Vs}$. These values agree well with the previously reported results evaluating the mobility of each material.

\section{Conclusion}

In-situ impedance spectroscopy (IS) observations of the photoconductivity of the carriers induced by photoirradiation in organic hetero-junction structured photovoltaic devices are presented. Analyzing the IS data showed the existence of two components with different relaxation times, which originated from the donor and acceptor 


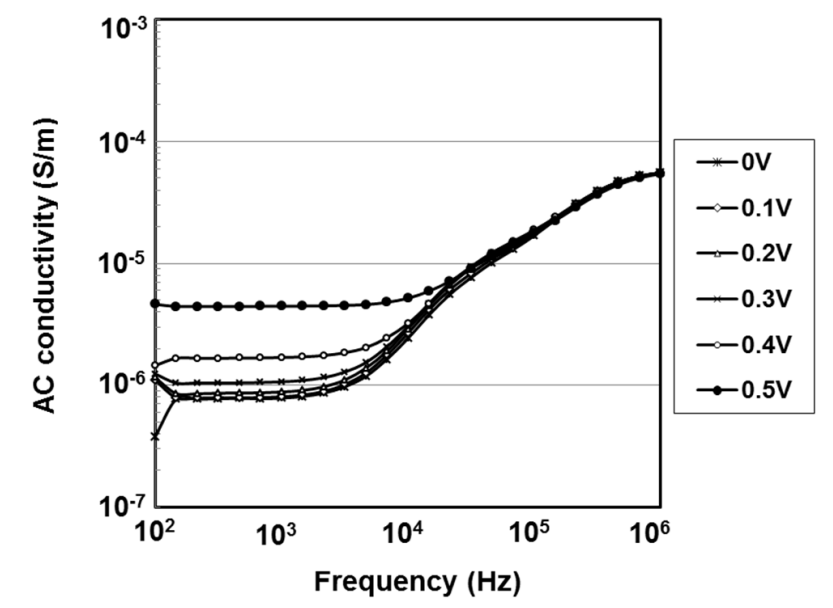

Figure 4. Frequency dependence of the AC conductivity under different DC bias voltages.

materials. The peak frequency of these components shifted as a function of the light intensity and they had the same slope. The conductivity originated from the holes and electrons that were photo-induced by photoirradiation was used to calculate the mobility ratio. The mobilities of the CuPc and C60 layers were calculated from the conductivities and were in the orders of $10^{-4}$ and $10^{-3} \mathrm{~cm}^{2} / \mathrm{Vs}$, respectively. For the first time, in-situ measurements of the photoconductivity were performed by using an actual device in the low-voltage region in which OPV devices are operated. These results serve as a guideline for the future development and improvement of organic semiconductor devices based on multilayer structures.

\section{References}

[1] Campbell, A.J., Bradley, D.D.C. and Lidzey, D.G. (1997) Space-Charge Limited Conduction with Traps in Poly (phenylene vinylene) Light Emitting Diodes. Journal of Applied Physics, 82, 6326-6342. http://dx.doi.org/10.1063/1.366523

[2] Brütting, W., Riel, H., Beierlein, T. and Riess, W. (2001) Influence of Trapped and Interfacial Charges in Organic Multilayer Light-Emitting Devices. Journal of Applied Physics, 89, 1704. http://dx.doi.org/10.1063/1.1332088

[3] Martens, H.C.F., Pasveer, W.F., Brom, H.B., Huiberts, J.N. and Blom, P.W.M. (2001) Crossover from Space-ChargeLimited to Recombination-Limited Transport in Polymer Light-Emitting Diodes. Physical Review B, 63, Article ID: 125328. http://dx.doi.org/10.1103/PhysRevB.63.125328

[4] Nguyen, N.D., Schmeits, M. and Loebl, H.P. (2007) Determination of Charge-Carrier Transport in Organic Devices by Admittance Spectroscopy: Application to Hole Mobility in $\alpha$-NPD. Physical Review B, 75, Article ID: 075307. http://dx.doi.org/10.1103/PhysRevB.75.075307

[5] Okachi, T., Nagase, T., Kobayashi, T. and Naito, H. (2008) Determination of Charge-Carrier Mobility in Organic LightEmitting Diodes by Impedance Spectroscopy in Presence of Localized States. Japanese Journal of Applied Physics, 47, 8965. http://dx.doi.org/10.1143/JJAP.47.8965

[6] Garcia-Belmonte, G., Munara, A., Bareaa, E.M., Bisquerta, J., Ugarteb, I. and Paciosb, R. (2008) Charge Carrier Mobility and Lifetime of Organic Bulk Heterojunctions Analyzed by Impedance Spectroscopy. Organic Electronics, 9, 847-851. http://dx.doi.org/10.1016/j.orgel.2008.06.007

[7] Jørgensen, M., Norrman, K. and Krebs, F.C. (2008) Stability/Degradation of Polymer Solar Cells. Solar Energy Materials and Solar Cells, 92, 686-714. http://dx.doi.org/10.1016/j.solmat.2008.01.005

[8] Ahles, M., Schmechel, R. and von Seggern, H. (2004) N-Type Organic Field-Effect Transistor Based on InterfaceDoped Pentacene. Applied Physics Letters, 85, 4499. http://dx.doi.org/10.1063/1.1818737

[9] Torres, I. and Taylor, D.M. (2005) Interface States in Polymer Metal-Insulator-Semiconductor Devices. Journal of Applied Physics, 98, Article ID: 073710. http://dx.doi.org/10.1063/1.2081109

[10] Redecker, M., Bradley, D.D.C., Inbasekaran, M. and Woo, E.P. (1998) Nondispersive Hole Transport in an Electroluminescent Polyfluorene. Applied Physics Letters, 73, 1565-1567. http://dx.doi.org/10.1063/1.122205

[11] Redecker, M., Bradley, D.D.C., Inbasekaran, M. and Woo, E.P. (1999) Mobility Enhancement through Homogeneous Nematic Alignment of a Liquid-Crystalline Polyfluorene. Applied Physics Letters, 74, 1400-1402. 
http://dx.doi.org/10.1063/1.123563

[12] Poplavskyy, D., Nelson, J. and Bradley, D.D.C. (2003) Ohmic Hole Injection in Poly(9,9-dioctylfluorene) Polymer Light-Emitting Diodes. Applied Physics Letters, 83, 707-709. http://dx.doi.org/10.1063/1.1596722

[13] Poplavskyy, D. and Nelson, J. (2003) Nondispersive Hole Transport in Amorphous Films of Methoxy-SpirofluoreneArylamine Organic Compound. Journal of Applied Physics, 93, 341-346. http://dx.doi.org/10.1063/1.1525866

[14] Poplavskyy, D., Su, W.C. and So, F. (2005) Bipolar Charge Transport, Injection, and Trapping Studies in a Model Green-Emitting Polyfluorene Copolymer. Journal of Applied Physics, 98, Article ID: 014501. http://dx.doi.org/10.1063/1.1941482

[15] Khan, R.U.A., Bradley, D.D.C., Webster, M.A., Auld, J.L. and Walker, A.B. (2004) Degradation in Blue-Emitting Conjugated Polymer Diodes Due to Loss of Ohmic Hole Injection. Applied Physics Letters, 84, 921-923. http://dx.doi.org/10.1063/1.1645982

[16] Tse, S.C., Fong, H.H. and So, S.K. (2003) Electron Transit Time and Reliable Mobility Measurements from Thick Film Hydroxyquinoline-Based Organic Light-Emitting Diode. Journal of Applied Physics, 94, 2033-2037. http://dx.doi.org/10.1063/1.1589175

[17] Saeki, A., Tsuji, M. and Seki, S. (2011) Direct Evaluation of Intrinsic Optoelectronic Performance of Organic Photovoltaic Cells with Minimizing Impurity and Degradation Effects. Advanced Energy Materials, 1, 661-669. http://dx.doi.org/10.1002/aenm.201100143

[18] Saeki, A., Yoshikawa, S., Tsuji, M., Koizumi, Y., Ide, M., Vijayakumar, C. and Seki, S. (2012) A Versatile Approach to Organic Photovoltaics Evaluation Using White Light Pulse and Microwave Conductivity. Journal of the American Chemical Society, 134, 19035-19042. http://dx.doi.org/10.1021/ja309524f

[19] Azuma, H., Asada, K., Kobayashi, T. and Naito, H. (2006) Fabrication of $\alpha$ - and $\beta$-phase Poly(9,9-dioctylfluorene) Thin Films. Thin Solid Films, 509, 182-184. http://dx.doi.org/10.1016/j.tsf.2005.09.032 
Scientific Research Publishing (SCIRP) is one of the largest Open Access journal publishers. It is currently publishing more than 200 open access, online, peer-reviewed journals covering a wide range of academic disciplines. SCIRP serves the worldwide academic communities and contributes to the progress and application of science with its publication.

Other selected journals from SCIRP are listed as below. Submit your manuscript to us via either submit@scirp.org or Online Submission Portal.
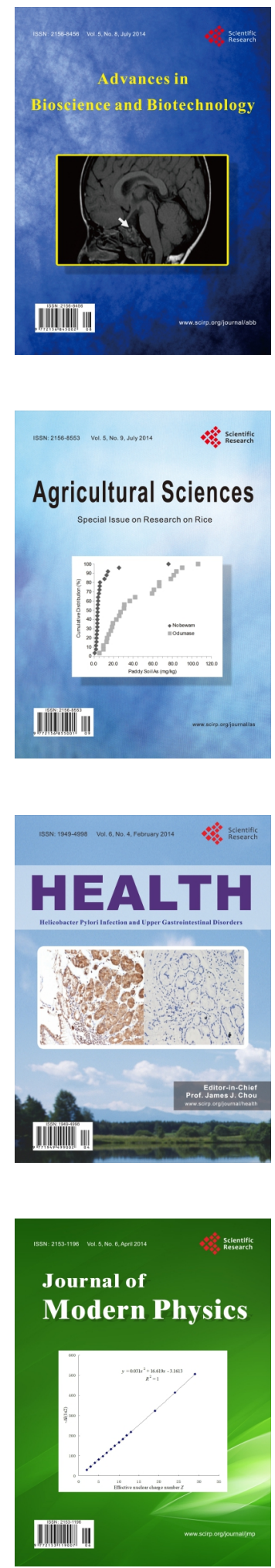
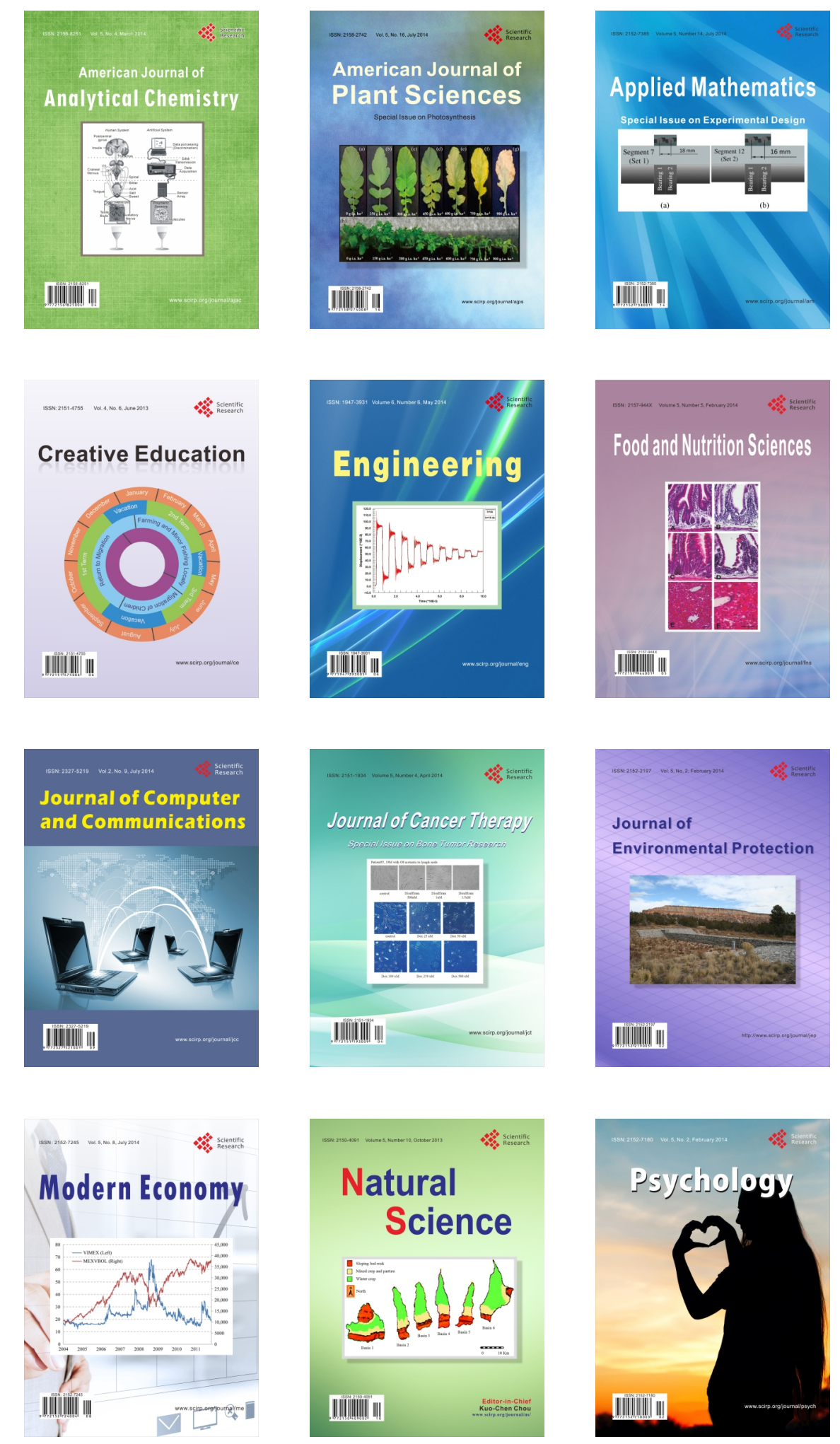